Vibhuti ,Jha ${ }^{2}$

\title{
Employee Performance in High Stressed Indian Garment Industry; A Study on Design \& Production House - Style Variations in New DelHI (INDIA)
}

\begin{abstract}
:
Being universal phenomenon, stress is experienced in everyday human life especially among individuals who workin different industrial set-ups at various levels of jobs. With changing work expectations, competition \& environment, increasing workloads and work place politics, stress has become an integral part of employees' life and affects individual performance. Also, due to an employee's psychological and physiological reactions to work situation factors directly or indirectly influence the stress to appears, as resultant. Though certain level of work stress instigates the efficiency of work in positive but more stress causes negative impact on individual employee and in turn to organization too.
\end{abstract}

\section{Keywords:}

work stress; work experience; job performance; skill based industry; competitive businesses

\section{Author's data:}

${ }^{1}$ Sharmila, Sharan, PhD , Royal Thimphu College, Bhutan, sharmilasharan@rrtc.bt

${ }^{2}$ Vibhuti, Jha,.,Roval Thimphu College,Bhutan,viha@rtc.bt

International Journal - VALLIS AUREA • Volume 7 • Number 1 • Croatia, June 2021

UDK 687:005.336.1-057.16(540); DOI 10.2507/IJVA.7.1.2.77

Employees handle such stress without letting it influence their performances but fail to do so with growing work stress beyond certain level. On organization side, it also depends upon type of industry and nature of competition faced by the organization in market. On individual side, this stress impact on performance varies with work experience, demographics and length of service years. In order or assess workplace stress and its influence on individual employee, this study is done on a garment manufacturing organization in India, which is prone to high work stress due to its competitive nature of business. 


\section{Introduction}

Since industrialization era, "job performance' is a content that has been extensively on priority in all industrial and organizational psychologies due to its importance in success of an organization. Success of a company depends on the employees' job performance and as job responsibilities of employees require to carry out several functions at a workplace environment, it brings satisfying as well as stressor effects on them.

Being universal phenomenon, stress is experienced in everyday human life especially among individuals who work in different industrial set-ups at various levels of jobs. With changing work expectations, competition and work place, increasing workloads and work place politics stress has become an integral part of employees' life and affects individual performance at work place, beyond any doubts. Also, due to an employee's psychological and physiological reactions to uncomfortable, undesirable work situations, threats \& uncertainties of workplace environment and many more factors directly or indirectly influence the physical \& mental health cause this stress to appears, as resultant

Experts have argued that stress is a dynamic process, which keeps on changing in accordance to the roles played by individuals in changing environment of the workplace. Especially if we talk in context to workers in a precision industries or skill based industries, they undergo high work stress levels which is derived from key elements like work, non-work or personal factors. The impact of workplace stress affects the productivity and quality of employees' physical performance and its psychological impact could stretch beyond the work environment and lead to unhealthy lifestyle habits, frustrations, changed behaviors and inturn resulting into declining health conditions, undue defense mechanisms and destructive attitudes.

In highly competing industries like ready to wear garments, job profile of an employee gives rise to tremendous pressures also to the employees, which mostly gets induced from deadlines to meet, overload of work, difficult tasks, vulnerable clients and internal politics etc. In dealing with those, it generates significant pressures on the employees. Such pressures make a job and its working environment stressful and result in dysfunctional work performance, behavioral changes and loss of effectiveness, if the stressors aren't taken care of on time.

In India, the market environment of the ready wear garment sector is very dynamic compared to other products, because of it short product cycle, ever changing trends, high levels of precision \& skill requirements in output and highest levels of market competition. In result, most professionals in this sector of high precision \& skill experience high levels of work stress as resultant. Multitasking, limited opportunities and personal factors like gender, age and work experience are also making significant impact to such stress in this field. This workstress is very critical in context to human behaviors and induces positive or negative reaction towards one's job.

If we talk about core stressors of the sector, there are many factors that contribute to the "high 
level" of work stress in this unique sector. A few core stressors of this sector are summarized as:

- $\quad$ Higher employer expectation to maintain quality \& quantity of work output,

- $\quad$ Expectations of high skill levels from employees,

- Changing customer expectations and trends,

- $\quad$ High precision levels in competitive mass product manufacturing,

- Meeting deadlines and fear of losing market to competitors,

- $\quad$ Fear of substitution by cheaper products from countries like china/Korea

Such factors (not limited to) are accounted for instigating work stress among professionals in this sector. Such factors affect the job performance of employees in negative, as expressed and observed, in general as workplace stress and job performance are two interlinked crucial issues that affect the individual working and day to day operations of an organization. Although , numerous studies related to stress and performance issue have been carried out in companies belonging to almost all sectors including manufacturing, production, banking, education etc. but rarely has the study related to these issues been carried out in ready to wear industry in India especially in New Delhi. This study is carried out to get some insight from this industry as well.

\section{Literature Review}

Employees are vulnerable to high levels of stress and this is associated to burnout, job turnover, job dissatisfaction, lower organizational commitment and more importantly decrease in job performance. In turn, this impacts the fastest of declines of organizations engaged in garment manufacturing. This has been observed in past years in all countries. Retaining skilled professionals in production, marketing and technology has become vital in the sector where cut throat competition is prevailing at its peak. Updating with changing trends, handling disruptive challenges, tackling with everyday new entrants and countering to competitor offerings are the key requirements and causes of pressures in all sectors. Such factors lead to high work stressors resulting into high turnover of employees due to stressful working and companies are rather forced to strategize retaining skilled employees. [1]

Considering the need to retaining skilled professionals in companies, it is important for the employer to identify the sources of stress and reduce the level of their employees' stress, depending upon work environment and desired expectations of their companies arising out of market requirements. Organizational conditions, market climate and work culture have been associated with work stress on the employees which results in actions such as intention to leave job, degradation in quality, inconsistency of product output, low job performance and loss of work satisfaction etc. which in turn, harm the company performance to lose the competitive edge. [2] 
Job stress is also induced in employees because of the dynamic nature of market, where the company operates, which includes factors like need of rapid growth and quick reorganization of resources, demand for timely technological advancements. Such elements lead to loss of productivity after certain level of work stress which is considered to be essential for work performances in organizations. [3]

For a company certain level of stress is essential among its staff to trigger their performance levels. The employers may take pressure to shortening the deadline span for a project completion. To complete the project well on time, the employees will work within the limited timeframe to complete their work by taking stress and perform well but this does not mean that stress levels should increase at a constant pace to get more work from him. Figure 1 below depicts the philosophy to achieve efficiencies. [4]

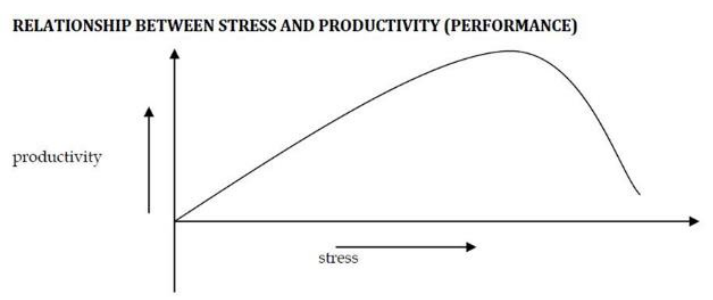

Figure 1: Relationship between stress and performance Ievels. Source: International Journal of Management Focus, A study on Relationship between Stress Management \&Workability, 2013.

The above figure shows the inverted U relationship between stress and productivity. As we see in the above figure, up to a certain stress Ievel, the performance curve increases positively but once, the stress cuts of its maximum level for the employee, we see a slump in his performance. This is what an organization should try to minimize. So it is best to maintain the work stress levels at moderate to achieve better efficiency in the company's performance levels.

The theory of role dynamics gives us a framework to understand role conflicts and ambiguity in companies that affects the stress levels of the employees. This theory suggests that performance will be a function of both the individual and of the organization. The role theory also provides the basis to measure the performance of the professionals. According to the role theory, individuals' role expectations are influenced by both their personal attributes and the work context in which they exist [5]. Based on this theory, the following reviews related to this research has been made:

- Job-Related Tension Index (JRTII) has been used to measure the levels of job stress generated by ambiguous roles and contradictory job demands. Developed by Kahn, R. L., Wolfe, D. M., Quinn, R. P., Snoek, J. D., \& Rosenthal, R. A. (1964), it identifies four stressors:

- work conflict,

- resource inadequacy,

- work overload and

- work ambiguity.

Based on the theory of role dynamics, the 15 elements are identified under four stressors to measure the job stress on employees.

- $\quad$ Role-Based Performance Scale (RBPS) has been used in order to measure job performance. Developed by Welbourne, Johnson and Erez (1998), it is a 20 item scale which includes the measurement 
of various roles performed by an employee in a work setting such as: Job, organization role, career role, team role and innovator role. [6]

People are considered very important in business today as the whole business depends on their effective performance .Low levels of employee performance could lower firm's profitability and lead to failure .The factor that explains organizational performance is job performance, which indicates how well an employee performs [7] stress creates severe pressure on workplace health. Although the connection between quality management, workplace stress and health is beginning to be well established through various studies. Examining associations between quality management values, workplace health and workplace stress is vital for industries. [8]

\section{Objectives of study}

This study is done on a garment manufacturing organization in New Delhi-India which is prone to high work stress due to its competitive nature of business i.e. ready to wear segment. For this purpose, company namely style Variation -New Delhi was identified considering their competitive sustained presence in garment manufacturing \& marketing in Indian as well as global markets. This study aims to determine effect of work place stress on the job performance of employees in this high skill \& precision based industry. Along with that, this study also aimed to look into analyzing any effect of demographical factors and work experience on the job performance of employees considering the highest of competition prevailing in the sector, covering production as well as marketing areas. This research is focused on understanding impact of workplace stress on job performance of employees in this demanding sector. Also, aspects like gender, demographics of employees, service of work are also studied to understand their impacts on job performance.

Following key objectives are set for the study:

1. To study impact of work place stress on the job performance of employees in highly skilled and competitive industries like garments

2. To study effect of demographical factors like age , gender and length of service on the job performance of employees in such industries

3. To study individual and interaction effect of age \& work experience ( length of Service) on job performance of the employees in these competitive industries

\section{Methodology}

This research is focused on how workplace stress impacts the job performance of employees at style Variation - New Delhi [SV] which is linked to psychology and organizational behavior contexts. To obtain a better understanding of the occurrence, the required data was collected from middle and lower management employees of the company which is engaged in designing , production and marketing of ready to wear garments in Indian and overseas markets.

Following research design was taken up as conceptual frame workin the study, as indicated in Figure 2 below. 
- $\quad$ The figure represents factors that were measured through the JRTI and RBPS scales.
- $\quad$ Under the four factors of JRTI, 15 items were loaded and accordingly the responses on each of the items were analyzed.

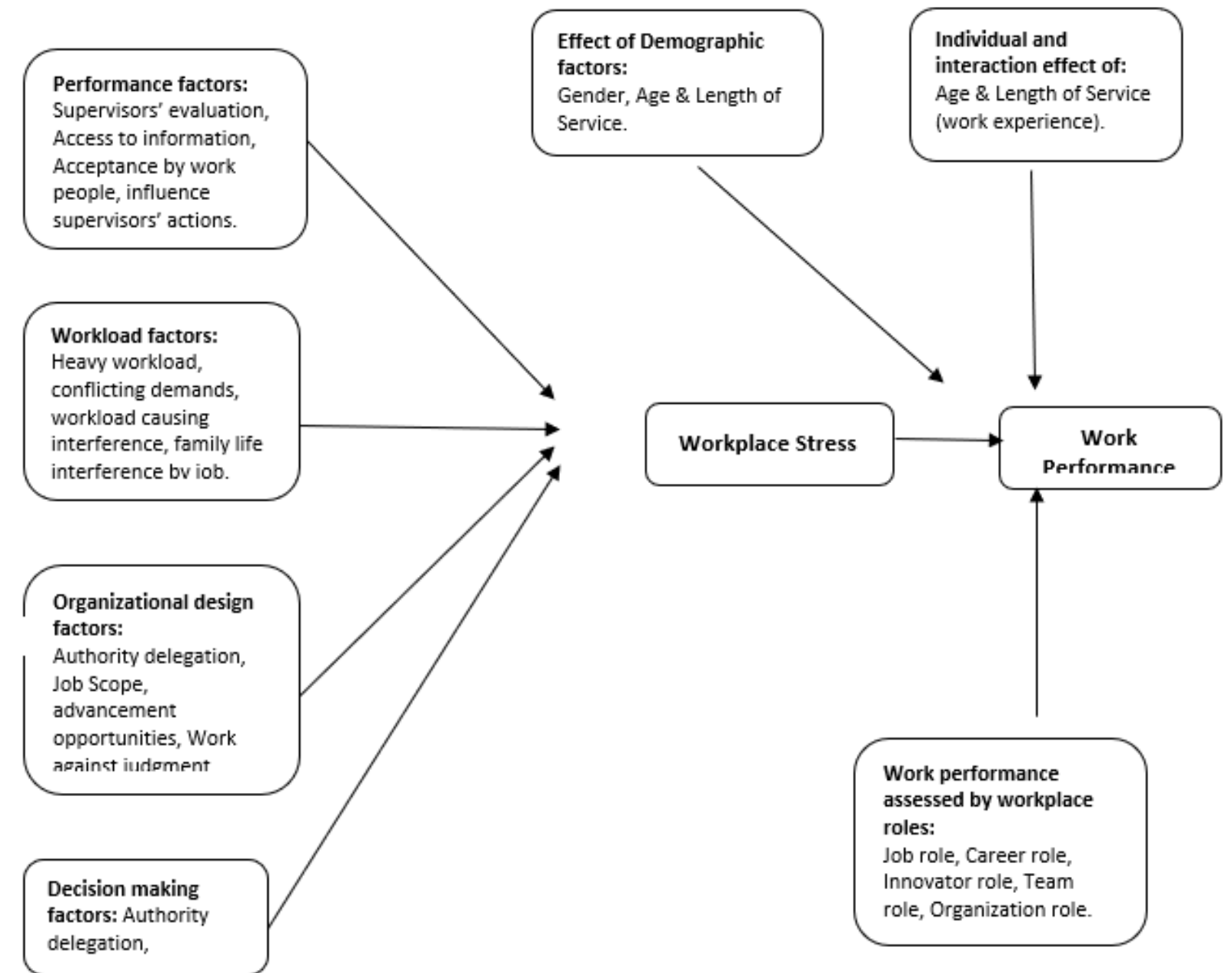

Figure 2: Conceptual Figure of the Study

\section{Conceptual elements in design}

\section{i. Performance factors}

It looks into evaluation of information access, work place acceptance, performance and ability to influence supervisor's actions in favor of the employee.

Performance factors: Supervisors' evaluation, Access to information, Acceptance by work people, influence supervisors' actions

\section{ii. Workload factors}

The level at which employees have to deal with heavy work demands that interferes with the efficiency of work execution.

Workload factors: Heavy workload, conflicting demands, workload causing interference, family life interference by job

\section{iii. Organizational Design factors}


Based on it, how much authority are each level of employees delegated with, clarity of job scope and how freely can employees execute their responsibilities without much management pressure.

Organizational design factors: Authority delegation, Job Scope, advancement opportunities, Work against judgment.

\section{iv. Decision Making factors}

It addressed the issues of work conflict that arises an employee doesn't feel equipped enough for his/her job and has to make decisions that affect lives of people around at work.

Decision making factors: Authority delegation, job responsibility

Work performance assessment by workplace roles:

For the 20 item of RBPS included the measurement of various roles performed by an employee in a work setting such as:

\section{i. Job and organization roles}

Both these roles represent the distinguishable extents of job performance. Job roles signify the traditional view of employee performance in terms of quality, quantity and accuracy of work. Whereas organization role indicate the organizational citizenship behavior where employees go beyond the call of their work duty to work for the well-being of the company.

\section{ii. Career role}

The ability of an employee to obtain the required skills in order to make necessary progress through the organization and at the same time how well can an employee increase their value to the organization by taking charge of their personal career planning.

\section{iii. Team role}

A crucial component to assess job performance, the importance of team roles as well as use of teams have dramatically increased over the last several years. This role evaluates the work performance based on quality team work result, helping out the group needs to ensure success for the firm.

\section{iv. Innovator role}

Organizations need employees who are creative on behalf of the entire firm, in order to remain competitive in the ever changing and complex work environments. It requires employees to behave in innovative ways, by not just applying ingenious skills but also contributing to the efficacy and flexibility of the organization as a whole.

\section{Field study}

Adopting convenience sampling, suiting to organization chosen, primary data was collected through a structured written questionnaire given to employees, one to one. After establishing sufficient rapport employees could give responses by sparing time after due permission of top management (which was also an indication of level of work stress prevailing in the sector]. The data was collected after explaining each item on the questionnaire to the respondents.

\section{i. $\quad$ Primary data}

A total of 40 samples were collected from the middle and lower management at SV, out of which 36 responses were found complete and flawless. It was observed that respondents were eager to fill 
out the questionnaire, as it was the first time that this type of study was being conducted and they wanted to contribute towards better organizational change management process to improve the quality of their work environment, product development processes, quality Assurance practices, sustaining capabilities in changing market dynamics and reducing work stress causing out of pressures in these fields. They were more interested in identifying \& minimizing bottlenecks that the company is experiencing towards improving on efficiency \& effectiveness levels.

After framing the questionnaire including JRTI \& RBPS items, a direct scoring format was created and distributed for the survey.

Following hypothesis are framed in for this study:

\section{ii. Hypothesis:}

H1: There is significant effect of job stress on job performance of SV employees.

H2: There is significant independent as well as interaction effect of age and length of service (work experience) on job performance of SV employees.

H3: There is significant effect of demographic factors like gender, age and length of service on job performance of SV employees.

\section{Data Analysis , findings and discussion}

The data collected; through questionnaire and one to one interaction \& explanation; were processed on SPSS. Different statistical analysis tools and techniques were used to achieve the stated research objective. Mainly, Independent sample Ttest, Analysis of Variance (ANOVA) and Multiple Regression Analysis were used to test hypothesis. The relationships between the study factors were analyzed using independent sample t-test, descriptive statistics, ANOVA and multiple regression.

Independent t-test is used to find out the level of significance in the relationship between the employee stress levels and the performance mean scores.

ANOVA is used to identify the subject effects of the independent demographical variables on the performance scores of the employees.

Multiple regression is used for drawing conclusions about the impact of selected demographical factors on the performance of SV employees.

\section{Findings}

\section{i. $\quad$ - test}

The Independent Sample T- test was used to assess whether the means of the two groupsviz. job stress and job performance were statistically different from each other or not.

Before conducting the I- test, the mean stress scores were categorized into high and low stress level categories. Then the independent I-test was run between the mean stress scores and the job performance scores.

Table 1: Independent t-test Summary table on effect of Job stress on Job performance 


\begin{tabular}{llllllll}
\hline Variable & $\begin{array}{l}\text { Stress } \\
\text { Levels }\end{array}$ & N & Mean & S.D & Df & T & $\begin{array}{l}\text { Sig. [2 } \\
\text { tailed] }\end{array}$ \\
\hline $\begin{array}{l}\text { Job Performance } \\
\text { Scores }\end{array}$ & Low & 15 & 70.80 & 11.736 & 24.69 & 1.763 & 0.073 \\
\cline { 2 - 5 } & High & 21 & 64.48 & 8.79 & & & \\
\hline
\end{tabular}

Source: Survey Data

From the above independent t- test table, the mean values show the significant effect of stress levels on the performance scores of the employees.

- High performance mean scores (70.80) is seen at low stress levels and low performance mean (64.48) are seen at high stress levels. This significance effect is seen at $90 \%$ confidence interval.

- The table result shows that there is a significant difference in the job performance mean scores with high and low job stress levels, [t (34)=1.763].

Therefore, $1^{\text {st }}$ hypothesis, i.e. "There is significant effect of job stress on job performance of SV employees" is well supported.

\section{ii. Analysis of Variance}

- Analysis of Variance (ANOVA) shows that there is no significant effect of age on the job performance of employees of $S V$, $[P=0.896, P>0.05]$. This indicates the age differences of employees do not determine job performance levels.

\begin{tabular}{llllll}
\hline Source & $\begin{array}{l}\text { Type III Sum of } \\
\text { Squares }\end{array}$ & Df & Mean Square & F & $\begin{array}{l}\text { Sig. } \\
\text { P }\end{array}$ \\
\hline Age & 27.835 & 2 & 13.918 & 110 & .896 \\
$\begin{array}{l}\text { Length of } \\
\text { Service(w.e) }\end{array}$ & 26.506 & 2 & 13.253 & .105 & .901 \\
$\begin{array}{l}\text { Age \& Length of } \\
\text { service(w.e.) }\end{array}$ & 232.360 & 3 & 77.453 & .613 & .612 \\
\hline Error & 3539.056 & 28 & 126.395 & & \\
Total & 165964.000 & 36 & & & \\
Corrected Total & 3823.556 & 35 & & & \\
\hline
\end{tabular}

R Squared $=.074$ (Adjusted R Squared $=-.157$ )

Source: Survey Data

Table 2: Analysis of Variance (ANOVA) 
- The table 2 above also shows that there is no significant effect of length of service (lyears in the type of job- work experience (W.e.e)] on job performance, [P=0.901, P>0.05].

- This indicates that the differences in years of employment experience do not determine levels of job performance.

- This table further showed that no significant interaction effect of age and length of service on job performance, $[\mathrm{P}=0.612, \mathrm{P}>0.05]$.

This result supports the hypothesis $2 \mathrm{i}$.e. there is significant independent as well as interaction effect of age and length of service on job performance

\section{iii. Multiple Regression Analysis (MRAJ}

Multiple Regression Analysis (MRA) to check the influence of demographical factors on job performance and stress levels.

\begin{tabular}{|c|c|c|c|c|}
\hline \multirow[t]{2}{*}{ Variables } & Unstandardized Coefficients & $\begin{array}{l}\text { Standardized } \\
\text { Coefficients }\end{array}$ & \multirow[t]{2}{*}{$\mathrm{t}$} & \multirow[t]{2}{*}{ Sig. } \\
\hline & Std. Error & Beta & & \\
\hline
\end{tabular}

$\begin{array}{lrrrrr}\text { Constant } & 69.253 & 17.547 & & 3.947 & .000 \\ \text { Age } & -.117 & .693 & -.034 & -.169 & .867\end{array}$

$\begin{array}{lllllll}\text { Length } & \text { of } & .169 & .982 & .035 & .172 & .864\end{array}$

service

Gender

2.627

4.378

.106

.600

.553

Dependent Variable: Job Performance scores

Source: Survey Data

Table 3: MRA with demographical factors as predictor variable for Job Performance

- $\quad$ From table 3 , the demographical factorlength of service is shown to have positive significant influence on the job performance scores on SV employees.
- The other demographic factor, age, has a negative impact on the job performance and is not statistically significant. 
- $\quad$ Gender here shows a comparatively relative relationship between the performance scores of male and female. As the B value of gender is 2.627, which means that given the equal age and the length of service in years for both genders, male are seen performing better in terms of their performance scores by 2.627 times than that of the females working at SV.

- $\quad$ Overall result shows that demographical factors do not have significant influence on the job performance.

Through this finding, hypothesis 3 is not supported as there is no significant effect of demographic factors on job performance .

\section{Conclusion and recommendations}

From this study it is clearly identified that the stress levels of the employees had a significant impact on the job performance among the employees of SV. The result fits into the theoretical framework of this study which states that highly stressed industry workers would show less performance than workers with low stress.

The demographic features such as age, gender and length of service of the employees did not have a significant effect on the stress levels or the job performance of the employees, however individual features such as gender did have a positive influence on the job performance levels of the employees and work experience had a positive influence on the stress levels of the employees.

This result indicates that rather than specifying age to determine whether one works poorly or well, it's more about providing skills \& work experience of work assigned to employee. Male or female will not matter after getting due skills of work requirements in such competitive industries.

This research was conducted while SV was planning to undergo an organizational change management process through which the company intends to implement the new objective setting and performance review system in order to be competitive in highly vulnerable market. Stress levels of such company needs to be considered while formulating the plans because employees' performances are shown to be expressively dependent on work stress. Evaluation of the stress levels at regular intervals is deemed necessary to come out effective and sustainable in manufacturing and market operations. As SV has gradually grown into a global company in recent years and employees have also sensed the pressure to work at par with international standard in order to meet product quality, work systems, technologies and deadlines, it is important to provide skills of work. and focusing on areas of systems and process. The company should also look out for ways to even out the gender composition of the employees to smother any possible adverse element on performance.

Greater the stress, the less productive the workforce becomes and there is no exceptions in business world. As a result of low productivity, cost of operation \& production for the company increases. With the growing requirements of quality, volume and deadlines in competitive business scenario, it is suggested that the company should go for skill training and work experienced recruits instead of depending on old employees only in order to reduce the burden of 
increasing workloads and deadlines of international clients. This will also help in enhanced performances by the staff especially in lower and middle management.

In one to one interaction, this was also pointed out that job performance also depends on the working environment, which requires to be encouraging, inclusive and supportive. Activities that allows inclusive engagement of employees is much needed and hence company should work on creating organizational citizenship behaviors for handling challenges of market and production/operation activities.

Developmental opportunities for employees to enhance knowledge \& skills in order to improve capacity to handle large amount of work pressures can also be implemented by the organization.

\section{Limitations and further scope}

Study is conducted in an organization with limited samples of convenience that could lead to different results on objectives from other studies and may not hold good to other organizations.

The path for further study by other researchers on this topic has to be strengthened in order to find out how variables like company support and social support influence the stress levels an impact the job performance within the surveyed population of this study.

So in conclusion, this research has assisted SV to identify the loop areas which will help them to make proper decisions in order to moderate stress levels and improve company performance. This could help other organizations in the ready to wear garment sector.

\section{Bibliography}

[1] Ashfaq Ahmed, D. M. [2013). Effects of Job Stress on Employees Job Performance A Study on Banking Sector of Pakistan. IOSR Journal of Business and Management, 61-68.

[2] Campbell, J. M. (1993). A theory of performance. In E. Schmit, W. C. Borman \& Associates [Eds.]. In Personnel Section in Organizations (pp. 35-70). San- Fransisco: Jessey-Bass.

[3] Arbabisarjou A., A. Z. [2013). The relationship between job stress and performance among the hospital Nurses. World of Sciences Journal, 2, 181188.

[4] M.Lakshmi, D. G. [2013). A study on relationship between stress management and workablity. International Journal of Management Focus, 1-5. [5]0rgan, D. (1988). A restatement of the satisfaction-performance hypothesis. Journal of Management,14, 547-557.

[6] Welbourne, Johnson and Erez (1998), Role-Based Performance scale (RBPS ], The Academy of Management Journal 41[5], 540-555

[7] Jawahar, D, (2011) Perceptual Difference of Role based Performance -A Gender stud, International Journal of Business, Humanities and Technology Vol. 1 No. 3; November 2011

[8] Lagrosen ,\$, (2014) Workplace stress and health - the connection to quality management, International Journal of Quality and Service Sciences, 6[4], 387-398. 


\section{References}

[1] Ahmad, S. I. [n.d.]. The Impact of Stress on employee Productivity, Performance and Turnover: an important managerial issue . Retrieved from Academia: https://www. academia.edu

[2] Anderson E.S, C. S. [2002). Formal Organizational Initiatives and Informal Workplave Practices: Links to Work-Family Conflict and Job-Related Outcomes. Journal of Management,28.

[3] Baron, M. A. (2007). Performance management: A strategic and intergrated approach to acheive success. 3rd Edition. Mumbai: Jaico Publishing House.

[4] Beehr, A. J. [2000]. Work stressors \& Coworker support as predictor of Individual strain and Job Performance. Journal of Organizational Behavior, 21 (4), 391- 405 .

[5] Bhagat, J. M. (1987). Meaning and measurement of stressors in work environment.

[6] Corpley, M. S. (1999). Job Strain and psychiatric morbidity. Psychological Medicine, 29, 1411-1416.

[7] Groen, B. W. (2012). Why do employees take more initiatives to improve their performance after co-developing perfromance measures? A field study. Management Accounting Research, 120-141. [8] Hamlett, C. \& [n.d.]. How Stress Affects your Work Performance. Retrieved from http://smallbusiness.chron.com/stress-affectswork-performance-18040.html

[9] Jamal, M. \&. (1992). Shift work and departmenttype related to job stress, work attitudes and behavioral intentions: A study of nurses. Journal of Organizational Behavior, 13[5], 449-464.
[10] Koopmans, L. B. [2011]. Conceptual Framework of Individual work performance: a systematic review. JOEM, 53[8].

[11] Lazarus, R. [1991]. 'Psychological stress in the workplace' in P.L. Perrewe [Ed.J, Handbook of job stress. Journal of Social Behavior and Personality, 6,1-13.

[12] Lloyd, C. K. [2002]. Social work, stress and burnout: A review. Journal of Mental Health,11, 210226.

[13] Nikki R. Wooten, S. B. (2010). Factor Structure of Job-Related Tension Index among Social Workers. Research on Social Work Practice, Vol :20, No: $1,74-86$.

[14] 0j0, B. B. (2014). Impact of Job Stress on the Job Performance of Nigeria Security and Civil Defence Corps Members. Research on Humanities and Social Sciences, Vol. 4, No. 26, 166-175.

[15] Ortqvist, D. \&. (2006). Prominent consequences of stress: A meta-analytics review. International Journal of Stress managemnt, 13,399-422.

[16] Qadoos Zafar, A. A. [2015). Influence of Jon Stress on Emplovee Performance in Pakistan. American Journal of Social Science Research, Vol.1, No.4, 221-225.

[17] Robbins, S. [1998). Organizational Behaviour, 8th edition. Englewood Cliffs, Prentice_Hall International Inc.

[18] Schein, E. (1980). Organizational psychology. Eaglewood Cliffs, NJ: Prentice-Hall.

[19] Schuler, R. [1980]. Definition ad conceptualization of stress in organizations. Organizational behavior and Human Performance, 25, 184-215. 
[21] Thoits, P. (1991]. On merging identity theory and stress research. Social Psychology Quartely, 54, $101-112$.

[20] Van Maanen, J. \&. (1979). Toward a theroy of organizational socialization. In B.M Staw [Ed.]. In Research in organizational behavior (pp. 209-264). Greenwich, CT: JAI Press.

[23] Viswesvaran, C. \&. (2000). Perspectives on models of job performance. International Journal of Selection and Assessment, 8, 216-227. 